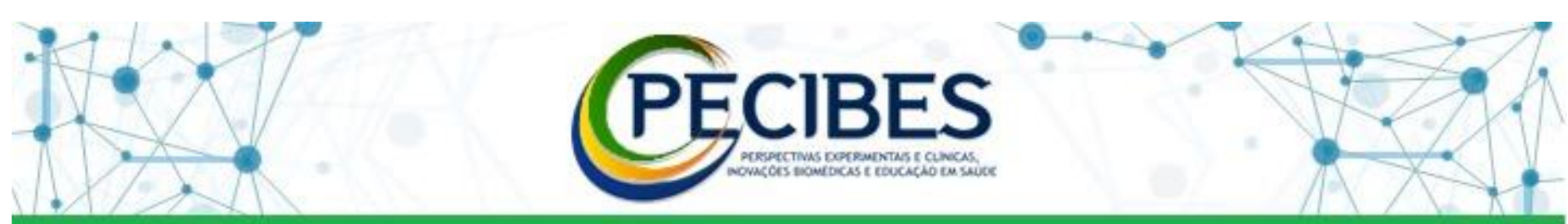

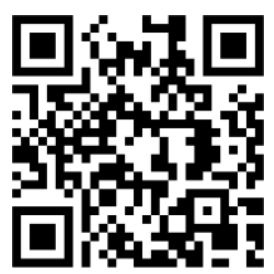

http://www.seer.ufms.br/index.php/p ecibes/index

\footnotetext{
*Autor correspondente:Ygor Thiago Cerqueirade Paula, Instituição-UFMS. E-mail do autor:profygorthiago@gmail. com
}

Descritores: Assoalho pélvico. Exercícios físicos. Mulheres. Alta intensidade..

Key-words: Pelvic floor. Physical exercises. Women. High intensity.

\section{Prevalência das disfunções do assoalho pélvico em mulheres praticantes de cross training em Campo Grande - MS.}

\author{
Prevalence of pelvic floor dysfunctions in women practicing cross training in \\ Campo Grande - MS.
}

Ygor Thiago Cerqueira de Paula ${ }^{1}$; Vanessa de Souza Ferraz ${ }^{2}$; Ingrid Barbosa Ferreira ${ }^{3}$; Gabriela Gabbi ${ }^{3}$; Lorena Cornacini Martines ${ }^{3}$; Silvio Assis de Oliveira-Júnior ${ }^{4}$; Hugo Alexandre de Paula Santana ${ }^{4}$; Ana Beatriz Gomes de Souza Pegorare ${ }^{4}$.

1. Mestrando, Programa de Pós-Graduação em Ciências do Movimento, UFMS, Campo Grande -MS.

2. Colaboradora, Mestranda Programa de Pós-Graduação em Ciências do Movimento, UFMS. Campo Grande

3. Colaboradora, Graduanda do Curso de Fisioterapia, UFMS, Campo Grande - MS..

4. Docente Programa de Pós-Graduação em Ciências do Movimento, UFMS, Campo Grande -MS.

\section{Eixo Temático: Atenção Multiprofissional em Atividade física, Reabilitação e Desempenho Físico-Funcional}

\section{Resumo}

A prática de exercícios físicos com foco na alta intensidade, o cross training (CT) tem ganhado muitos adeptos, especialmente as mulheres. Apesar dos benefícios desta prática sobre o gasto energético e condicionamento físico, não se sabe os efeitos sobre o assoalho pélvico. Objetivo: Investigar a prevalência das disfunções do assoalho pélvico de mulheres praticantes de cross trainning em Campo Grande, MS. Métodos: Estudo transversal realizado com base no CONSORT, aprovado pelo Comitê de Ética da UFMS Número do Parecer: 4.825.155, composto por mulheres praticantes de cross training há pelo menos seis meses consecutivos. Avaliação por meio de questionários auto- administáveis e respostas confidenciais que seguem: International Consultation of Incontinence Questionnaire - Short Form (ICIQ - SF), Questionário do Inventário de Socorro do Assoalho Pélvico (PFDI-20). Resultados Parciais: 56 mulheres com idade média de 34,83 anos ( 16 a 44 anos) responderam aos questionários. A maioria casada, no menacme, com com média de tempo de prática de CT de 32,3 meses. A prevalência de disfunção do assoalho pélvico foi de $58,92 \%$, sendo que a incontinência urinária leve foi o sintoma mais prevalente, ocorrendo em 30,35\%; seguido da constipação intestinal com $19,64 \%$ e a dor na pelve ou vagina por 3,57\%. Em relação ao início destes sintomas, segundo auto-relato a maioria $(55,55 \%)$ sempre teve o problema desde a infância, $38,88 \%$ relataram que a disfunção foi desencadeada pelo parto (normal ou cesariana) ou gestação em apenas $5.55 \%$ relataram que os sintomas ocorreram após o início do treinamento com alta intensidade.Conclusão: Os resultados preliminares, indicam que a prevalência de incontinência urinária feminina encontrada nas praticantes de crosstraining é bem semelhante a prevalência encontrada na população de mulheres em geral (Milson \&amp; Gyhagen, 2019). Indicando que Cross training não tem impacto negativo significativo sobre o assoalho pélvico. 